\title{
FATIGUE LIFE PREDICTION FOR SOLDER INTERCONNECTS IN IGBT MODULES BY USING SUCCESSIVE INITIATION METHOD
}

\author{
Dipesh Kumbhakarna $^{1}$, F. B. Sayyad ${ }^{2}$

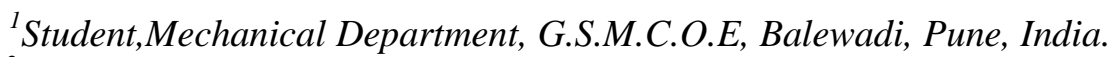 \\ ${ }^{2}$ Principle,Mechanical Department, G.S.M.C.O.E, Balewadi, Pune, India.
}

\begin{abstract}
Insulated gate bipolar transistors are the power semiconductors used for high current applications as a switching device. It is widely used in electrical and hybrid vehicles. It has become increasingly important to understand the reliability of these modules. The lifetime prediction is based on the assumption that the solder interconnections are the weakest part of the module assembly and that the failure cause is the inelastic deformation energy accumulated within the solder material. In this paper, the effects of thermo-mechanical fatigue of the solder layer interface have been investigated. A 2D model of 6 pack, 1200V IGBT module is used for the analysis. This study presents simulation of crack initiation and propagation under thermo-mechanical loading. Successive initiation technique is used to propagate crack in solder layer. A cyclic creep-fatigue damage under thermal loading is modeled using Energy Partitioning model to predict the fatigue life of an IGBT module.
\end{abstract}

Keywords: Successive initiation technique, IGBT, Energy partitioning model, Finite element analysis. $* * *$

\section{INTRODUCTION}

Now a day's many companies are working on hybrid vehicle and electrical vehicle. Main Inverter, DC/DC Converter, Auxiliary Inverters/Converters, Battery Management and On-board Charger are the components of HEV and EV. Figure 1 shows all the components.

Main Inverter: With an electric drivetrain, the inverter controls the electric motor. This is a key component in the car as, similar to the Engine Management System (EMS) of combustion vehicles, it determines driving behavior. Not only does the inverter drive the electric motor, it also captures energy released through regenerative breaking and feeds this back to the battery. As a result, the range of the vehicle is directly related to the efficiency of the main inverter.

DC/DC Converter: Different voltage levels are required by the various electronic components in an EV. High-voltage batteries with different voltage levels are currently available on the market. In addition, the power classes scale from $1 \mathrm{~kW}$ to $5 \mathrm{~kW}$ depending on the number of low-voltage applications. In EVs and HEVs, the DC/DC converter supplies the $12 \mathrm{~V}$ power system from the high voltage battery.

Auxiliary Inverters/Converters: Power on demand increases the efficiency of electric vehicles. With HEVs and EVs, former belt-driven devices classified as auxiliary drives have been electrified and integrated into the power system to deliver power on demand.Typical auxiliary systems supplied from the high-voltage battery include air conditioning, electronic power steering, PTC Heater, oil pumps and cooling pumps. As power from the battery is expensive, the challenge is to use the electric power as efficiently as possible.

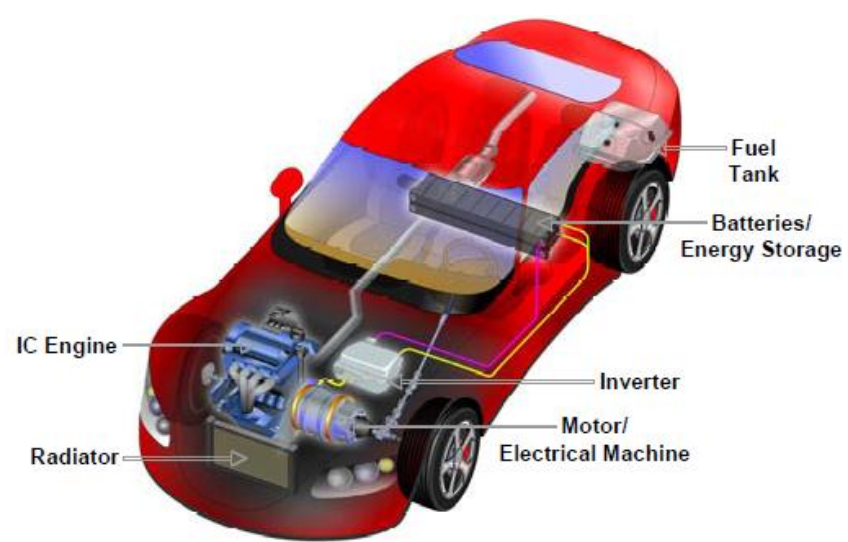

Figure 1. Shows components of HEV

Battery Management: The battery management system controls battery state during charging and discharging. Intelligent functionality is needed to extend the battery lifetime, which has a considerable impact on the total cost of ownership. The State of Health $(\mathrm{SoH})$, State of Charge (SoC) and Depth of Discharge (DoD) of the battery is permanently monitored.

On-board Charger: The battery in an electric vehicle is useless without a battery charger. And all electronic systems depend on the battery for power. With an on-board charger unit, the battery can be charged from a standard power outlet.

Power modules contain one or more semiconductor switches packaged together for easy connectivity. Power semiconductor modules play key role in power electronic system. The module can be used to enclosethyristors, diodes, FET, IGBT, or similar semiconductor switches. Nowadays, IGBTs are widely used as a result of good 
switching performance combined with fairly low conduction losses[1].IGBT is a four layer semiconductor device. It combines the voltage characteristics of a bipolar transistor and the drive characteristics of a MOSFET. The popularity of the IGBT has increased in recent years due to an increase in high voltage, high power application. They are available in the range of voltage rating from 300 to 1200 volts and current rating from 15 to 100 amps for a single die. IGBT modules have current rating well into the 100's of amps[2]. IGBT power modules are used in applications like automotive, traction, solar inverters. In hybrid electric vehicles, an electric power conversion system that includes an inverter and converter. They are used to convert the power generated by the engine into electrical energy, to charge and discharge a battery, and to drive the motor. The electric power conversion system typically uses an IGBT module as its main switching device. The failure modesthat have been identified are $\mathrm{Al}$ wire bond failure and crack in the solder layer between the base plate and substrate. Hence, the major concern from the reliability standpoint of view is the effect of thermal cycling on the insulating substrate to the base-plate solder interface. In this study, fatigue life prediction for solder interconnects in IGBT module by using E-P damage model and the SI method is done.

Prof. AbhijitDasgupta's group at University of Maryland has developed the successive initiation method and the examples of the use of the SI method are listed in this section. Dr. Juscelino Okura introduced SI method which can be used with any damage model[3].Ladani etal have discussed the use of SI method for lead-free BGA solder interconnects[3].In this research an experiment was designed and implemented on printing and reflow processes of $\mathrm{Pb}$-free solder interconnects in order to obtain errorseeded specimens. The specimens were characterized for voids and subjected to temperature cycling in order to evaluate the durability of specimens under thermomechanical loading. Statistical analysis of the void characterization as well as durability suggested the detrimental effect of voids. To verify this observation and in order to quantify the detailed influence of size, location, and volume fraction of voids, extensive modeling was conducted. A global-local modeling approach was used to model an error seeded solder ball with voids of different sizes and in different locations. An existing E-P model was modified by SI method and used to explicitly predict damage initiation and propagation in BGA solder joints. Two techniques were used to predict the life, averaging technique and successive initiation[3].James Gyllenskoghas reported the use of E-P model coupled with a SI technique to seethe initiation of crack and fatigue life prediction of the T-38 aileron lever for materials aluminum 2014-T6 and 7050-T74 [4].

\section{BACKGROUND ANDMOTIVATION}

Transistor is a three lead semiconductor device that acts as an electrically controlled switch or a current amplifier. BJT is a current controlleddevice, whereas FET and MOSFET are voltage controlled devices. The simple addition of an extra P-Njunction to the drain of the MOSFET changes the unipolar device into bipolar junction transistor. Combination of an insulated gate input and bipolar output makes the IGBT an excellent power switch for medium frequency and high voltage application. It combines features of both of these devices. Power electronics packaging technology has been developed for several generations, involving material upgrading, structure improvement and interconnection technique innovation. IGBT is presently one of the most popular devicedue to its wide ratings and switching speed of about $100 \mathrm{KHz}$, which makes it an easy voltage drive. Among the new power devices, IGBT devices are being more accepted and increasingly used in traction application such as locomotive, elevator, tram and subway.

The reliability of solder interconnects has always been an area of concern for microelectronics applications and continues to be a concern for power electronics as well. The study has been done by Hua Ye et al[5],on different failure modes in power electronic devices. They concluded that thermal cycling has significant effect on the solder layer reliability.They also stated that using finite element analysis and damage mechanics constitutive model it is possible to predict number of cycles to failure for solder layers. Sun et al[6] proposed CZM-based thermo-mechanical fatigue model. This model was developed to simulate the delamination process at the die-solder interface and to predict the lifetime of solder joint in IGBT module. In this model the path of the crack is known. To analyze this crack propagation process by delamination, a very thin layer of the solder joint at the die-solder interface is replaced by a layer of cohesive elements with the same thickness. The damage will be concentrated on this cohesive layer which allows simulating the progressive crack initiation and propagation taking place at the die-solder interface. The thickness of the cohesive layer will influence more or less the thermomechanically induced strain and stress fields. Hence, the effect of the thickness on the rate of damage evolution and the lifetime is studied.There are several different approaches like stress based approach, strain based approach, energy based approach and E-P damage model approach that are used to predict the life of solder joints. Present studyfocuses on fatigue life prediction for solder interconnects in IGBT module by using SI technique and E-P model. SI technique is used to propagate crack in solder layerinterface between substrate and base plate. E-P damage model approach is used to predict the lifetime of an IGBT module.E-P damage model assumes that cyclic fatigue damage is due to combination of elastic, plastic and creep deformation mechanism[3].

\section{FINITE ELEMENT MODELING}

A 2D IGBT module is used for the analysis. Module contains die soldered onto a DBC substrate which is made out of Aluminum Nitride (AIN) material for internal electrical insulation. It is then soldered to the base plate. Figure 1shows a 2D view of the multi-layer IGBT structure. Dimensions of each layer within the module construction are given in Table 1. 


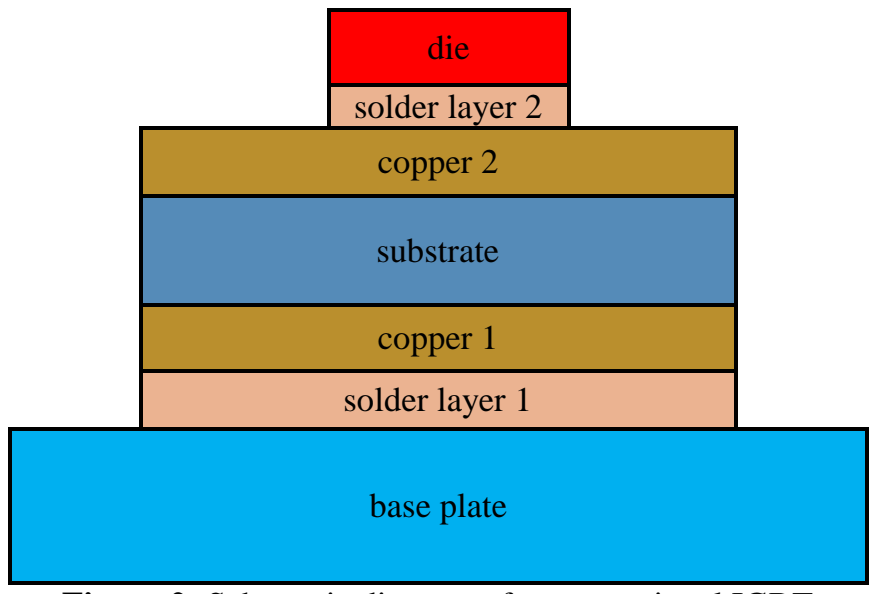

Figure 2: Schematic diagram of a conventional IGBT module[7].

Table 1. Dimensions of IGBT module

\begin{tabular}{|l|l|l|}
\hline Part & Material & Total Dimensions $(\mathrm{mm})$ \\
\hline Die & Silicon & $12.7 \times 12.7 \times 0.42$ \\
\hline Solder Layer 2 & SAC305 & $12.7 \times 12.7 \times 0.08$ \\
\hline Copper 2 & Copper & $41.7 \times 27.5 \times 0.3$ \\
\hline Substrate & AlN & $41.7 \times 27.5 \times 0.6$ \\
\hline Copper 1 & Copper & $41.7 \times 27.5 \times 0.3$ \\
\hline Solder Layer 1 & SAC305 & $41.7 \times 27.5 \times 0.21$ \\
\hline Base Plate & AlSiC & $174.1 \times 92 \times 3$ \\
\hline
\end{tabular}

Table 2. Material properties used for IGBT module

\begin{tabular}{|l|l|l|l|l|}
\hline Part & Material & $\begin{array}{l}\text { Young } \\
\text { Modulu } \\
\text { s (Gpa })\end{array}$ & $\begin{array}{l}\text { Poisson's } \\
\text { ratio }\end{array}$ & $\begin{array}{l}\mathrm{CTE} \\
\left(\mathrm{ppm} /{ }^{\circ} \mathrm{c}\right)\end{array}$ \\
\hline Die & Silicon & 131 & 0.3 & 2.8 \\
\hline $\begin{array}{l}\text { Solder } \\
\text { Layer 2 }\end{array}$ & SAC305 & MISO Properties & 20 \\
\hline Copper 2 & Copper & 121 & 0.3 & 17.3 \\
\hline Substrate & AlN & 330 & 0.24 & 4.5 \\
\hline Copper 1 & Copper & 121 & 0.3 & 17.3 \\
\hline $\begin{array}{l}\text { Solder } \\
\text { Layer 1 }\end{array}$ & SAC305 & MISO Properties & 20 \\
\hline $\begin{array}{l}\text { Base } \\
\text { Plate }\end{array}$ & AlSiC & 188 & 0.29 & 8.75 \\
\hline
\end{tabular}

Mesh sensitivity analysis was carried out where plastic work varies in the range of $+/-2 \%$. Figure 2 shows $2 \mathrm{D}$ finite element model of IGBT module. Element plane 183 is used for the analysis.

Material properties used for the analysis are given in Table 2. The solder layer is modeled using multi-linear isotropic properties and creep properties. The primary creep is neglected due to negligible damage in thermal cycling. Secondary creep is considered for the analysis. For solder materials Garofalo constants are used which are provided in Table 3[8].
Table 3. Secondary creep Garofaloconstants[8]

\begin{tabular}{|l|l|l|l|l|}
\hline Solder alloy & \multicolumn{5}{|c|}{ Creep properties } \\
\hline \multirow{3}{*}{ SAC305 } & $\alpha(\mathrm{MPa})^{-1}$ & $\mathrm{n}_{\mathrm{c}}$ & $\mathrm{A}$ & $\mathrm{Q}(\mathrm{J}-\mathrm{mol}-\mathrm{K})$ \\
\cline { 2 - 5 } & 0.18 & 2.3 & 6.07 & 55793 \\
\hline
\end{tabular}

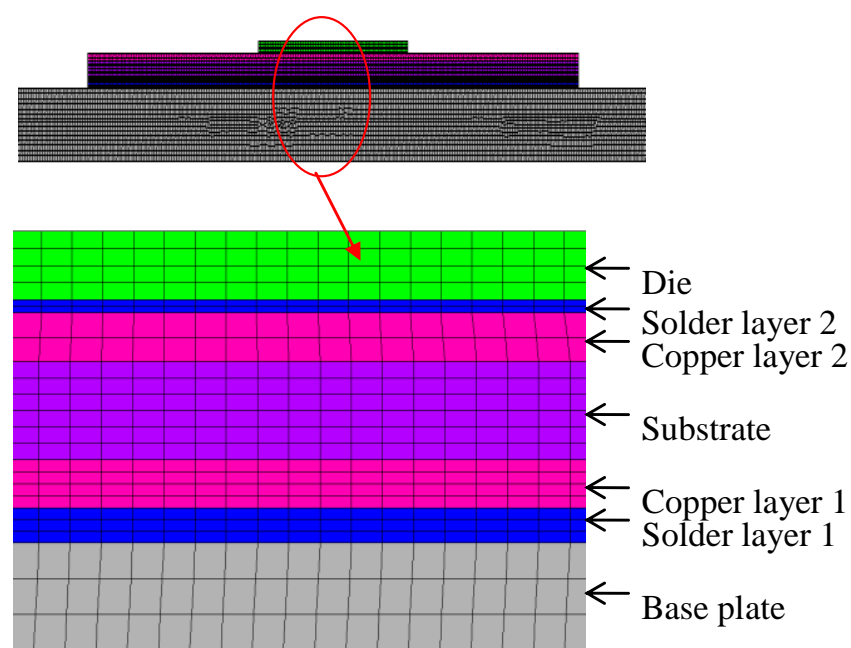

Figure 3: Two dimensional finite element meshed structure

IGBT module is subjected to thermal cycles rangingfrom$55^{\circ} \mathrm{C}$ to $160^{\circ} \mathrm{Cand}-40^{\circ} \mathrm{C}$ to $125^{\circ} \mathrm{C}$ with $15 \mathrm{~min}$ ramps and 15 min dwells. Figure 3 shows the thermal cycle range from $55^{\circ} \mathrm{C}$ to $160^{\circ} \mathrm{C}^{[5]}$. Plain strain condition is considered for the analysis. To apply boundary condition, all nodes at bottom surface of base-plate are fixed.

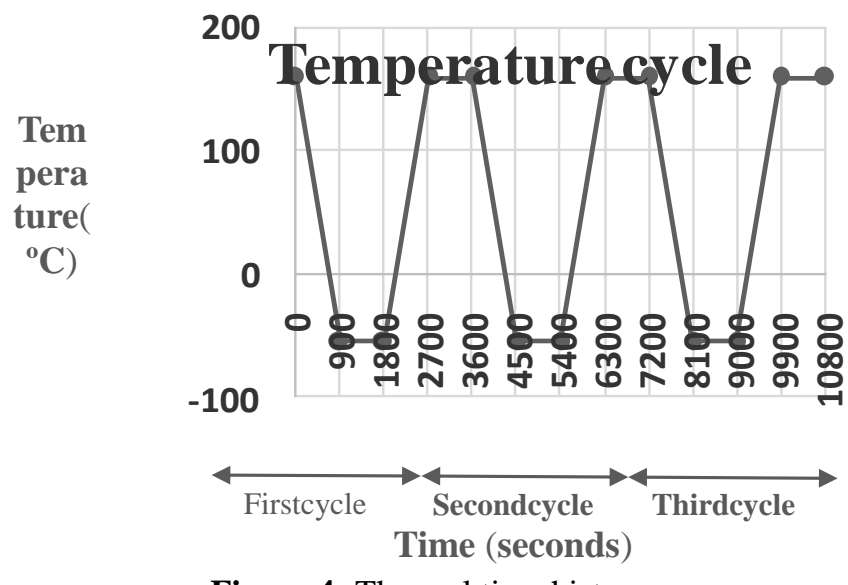

Figure 4: Thermal time history

\section{ENERGY PARTITIONING DAMAGE MODEL}

A cyclic creep-fatigue damage under thermal cycling is modeled using an E-P model. This model predicts cyclic creep fatigue damage based on deviatoric energy densities $\mathrm{U}_{\mathrm{e}}, \mathrm{W}_{\mathrm{p}}$ and $\mathrm{W}_{\mathrm{c}}$ for a typical load cycle. The damage due to each of these deformation mechanisms is determined by using a power law as provided in equation (1) to (3).

$\mathrm{U}_{\mathrm{e}}=\mathrm{U}_{\mathrm{e} 0} \mathrm{~N}_{\mathrm{e}}{ }^{\mathrm{b}}$

$\mathrm{W}_{\mathrm{p}}=\mathrm{W}_{\mathrm{p} 0} \mathrm{~N}_{\mathrm{p}}^{\mathrm{c}}$

$\mathrm{W}_{\mathrm{c}}=\mathrm{W}_{\mathrm{c} 0} \mathrm{~N}_{\mathrm{c}}^{\mathrm{d}}$

Figure 4.shows log-log plot of elastic, plastic and creep energy density (i.e. $\mathrm{U}_{\mathrm{e} 0}, \mathrm{~W}_{\mathrm{p} 0}$, and $\mathrm{W}_{\mathrm{c} 0}$ respectively ) versus cycles to failure. The exponents $\mathrm{b}$, $\mathrm{c}$, and $\mathrm{d}$ are their 
corresponding slopes. $\mathrm{W}_{\mathrm{p}}$ and $\mathrm{W}_{\mathrm{c}}$ are obtained from FEA analysis. Energy densitiesare calculated on those elements which are eliminated in every run.

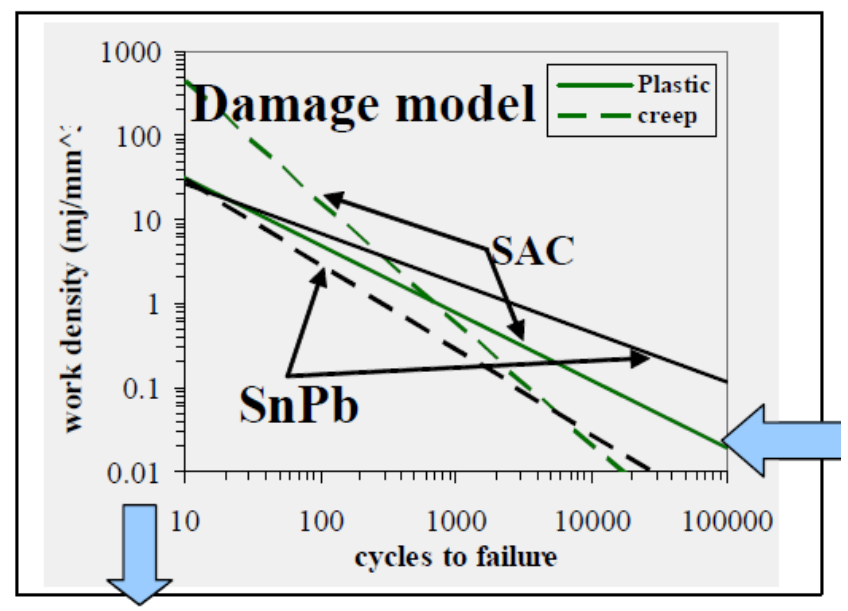

Figure 5: Work density verses number of cycles to failure [3]

Damage caused by each type of deformation can be calculated by substituting equations (1), (2) or (3) in equation (4). Damage is defined as reciprocal to number of cycles, as follows:

$$
D=\frac{1}{N_{f}}
$$

The total damage can be calculated by adding damage caused by elastic, plastic and creep deformation as seen in equation (5). Usually damage caused by elastic deformation is negligible.

$$
\begin{gathered}
D_{\text {total }}=D_{e}+D_{p}+D_{c} \\
\frac{1}{\mathrm{~N}_{\mathrm{f}}}=\frac{1}{\mathrm{~N}_{\mathrm{e}}}+\frac{1}{\mathrm{~N}_{\mathrm{p}}}+\frac{1}{\mathrm{~N}_{\mathrm{c}}}
\end{gathered}
$$

The total number of cycles to failure $\mathrm{N}_{\mathrm{f}}$ is calculated from equation (6)[3].

\section{SUCCESSIVE INITIATION METHOD}

The SI method was first introduced by Okura[3]. SI analysis involves several steps for damage initiation and propagation shown in Figure 5. SI method is implemented with the help of finite elements. The damage initiation site is first identified with the help of an E-P damage model, for a typical cyclic loading condition. Inelastic energy includes plastic and creep work per cycle. This energy is calculated using FEA for all the elements to estimate the amount of damage by an E-P damage model. The elements with maximum damage can be identified from contour plots. The initiation zone is recognized by selecting all elements which exceed a suitable damage threshold. In order to minimize number of runs and to facilitate reasonable computational time, damage threshold in our case was selected to be $60 \%$ of the maximum value of damage. The propagation path for maximum damage evolution is then monitored. Elements in the damage initiation zone areremoved from the structure by eliminating or killing the damaged elements. The cyclic loading is repeated on the remaining surviving structure and new damage zones are identified based on $60 \%$ of the maximum value of damage. The process is incrementally repeated, until a complete failure path is established and the critical solder joint loses its ability to carry any further loads[9].

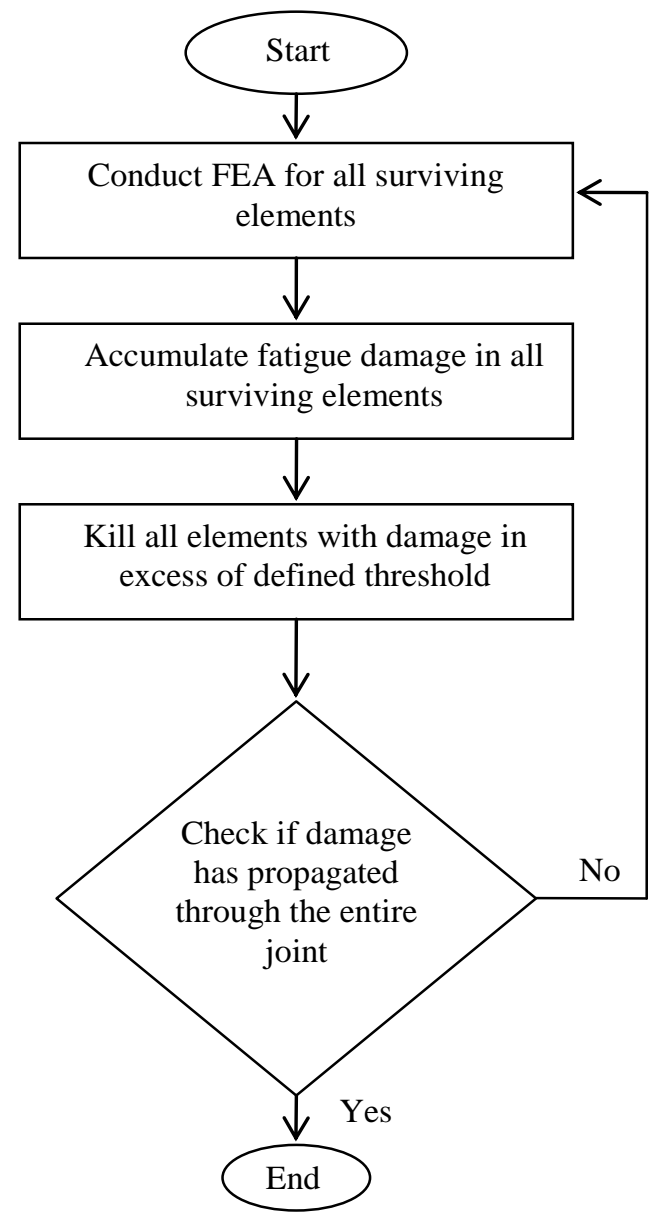

Figure 6: Damage propagation algorithm using SI method[9].

The total number of cycles to failure is calculated using MATLAB algorithm for thermal cycles ranging from $-55^{\circ} \mathrm{C}$ to $160^{\circ} \mathrm{C}$ and $-40^{\circ} \mathrm{C}$ to $125^{\circ} \mathrm{C}$. Calculations and tables shown below indicate values for thermal cycle $-55^{\circ} \mathrm{C}$ to $160^{\circ} \mathrm{C}$.Similarly, values have been calculated for thermal cycle $-40^{\circ} \mathrm{C}$ to $125^{\circ} \mathrm{C}$. Following is the procedure to calculate total number of cycles to failure. The term "Run" which is used in Table 4 to Table 10, refers to the thermal cycling applied on FEA model. Calculateddamage is accumulated in individual elements. The threshold damagecriteriais applied to kill the elements having value excess of defined threshold. Above run procedure is repeated till the complete delamination of solder layer is achieved.

Calculated creep work values for the runs are the per cycle work (i.e. creep work developed at the end of last thermal cycles). Table 4 shows the values from run 1 to run 56.Calculated plastic work values for the runs are the per 
cycle work (i.e. plastic work developed inthe last thermal cycle). Table 5 shows the values from run 1 to run 56.In following tables " 0 " value shows set of element having energy more than threshold.From values of creep work and plastic work estimate number of cycles due to creep and plastic work $\left(\mathrm{N}_{\mathrm{c}} \& \mathrm{~N}_{\mathrm{p}}\right)$ by using work density verses number of cycles to failure graph (Figure 4).

Following equations are used to calculate damage due to creep and plastic work.

$$
\begin{aligned}
& D_{c}=\frac{1}{N_{c}} \\
& D_{p}=\frac{1}{N_{p}}
\end{aligned}
$$

We get damage per cycle by addition of damage due to creep and plastic. Table 6 shows damage per cycle values.

$$
\text { Damage }{ }_{\text {Cycle }}=D_{c}+D_{p}
$$

Reciprocal of damage per cycle gives value of discrete $\mathrm{N}_{\mathrm{f}}$. Table 7 shows discrete $\mathrm{N}_{\mathrm{f}}$ values.

$$
\text { Discrete } N_{f}=\frac{1}{\text { Damage } / \text { Cycle }}
$$

Cumulative $\mathrm{N}_{\mathrm{f}}$ and total damage values are calculated simultaneously.First row of cumulative $N_{f}$ is equal to the first row of discrete $\mathrm{N}_{\mathrm{f}}$. First row of total damage is equal to first column value of cumulative $\mathrm{N}_{\mathrm{f}}$ divided by current column valueof cumulative $\mathrm{N}_{\mathrm{f}}$.
Second row of cumulative $\mathrm{N}_{\mathrm{f}}$ is calculated by following equation.

$$
\text { Cumulative } N_{f}=\frac{\left(1-(\text { Total Damage })_{\text {Previous row }}\right)}{(\text { Damage } / \text { Cycle })_{\text {current row }}}
$$

Above equation(11) is used to calculate remaining cumulative $\mathrm{N}_{\mathrm{f}}$ values. Table 8 shows cumulative $\mathrm{N}_{\mathrm{f}}$ values. For e.g.

$$
\begin{gathered}
\left(\text { Cumulative } N_{f}\right)_{@ \text { Run } 2}=\left[\frac{(1-0.704992)}{0.005516}\right] \\
=53.4759
\end{gathered}
$$

Second row of total damage is calculated by following equation.

\section{Total Damage =}

$1-$

$\left[\begin{array}{c}\left(\text { Cumulative } N_{f @ \text { Current row }}-\text { Cumulative } N_{f} @ \text { Run 2 }\right. \\ \times \text { Damage per Cycle } @ \text { current row value }\end{array}\right]$

Above equation(12) is used to calculate remaining total damage values. Table 9 shows total damage values.

For e.g.

$$
\begin{aligned}
& \text { Total Damage } @ \text { Run } 3 \\
&=1 \\
&-[(109.4635-53.4759) \times 0.00370] \\
&=0.792355
\end{aligned}
$$

Total $\mathrm{N}_{\mathrm{f}}$ is to addition of diagonal values of cumulative $\mathrm{N}_{\mathrm{f}}[10]$. Table 10 shows totalN $\mathrm{N}_{\mathrm{f}}$ values.

For e.g.

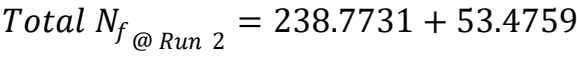

$$
\begin{aligned}
& =292.2491
\end{aligned}
$$

Table 4. Creep Work

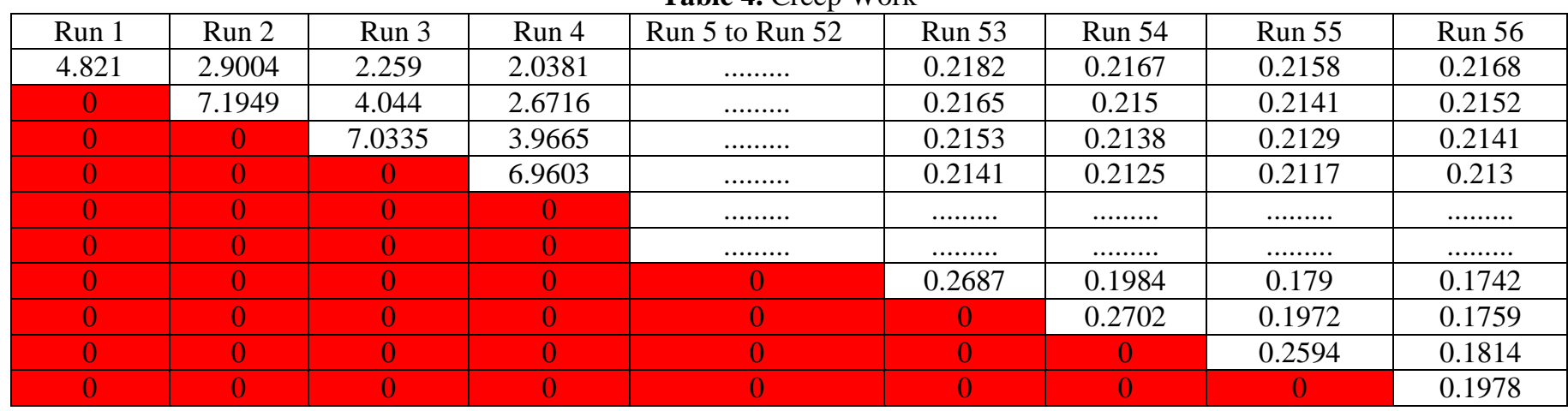

Table 5. Plastic Work

\begin{tabular}{|c|c|c|c|c|c|c|c|c|}
\hline Run 1 & Run 2 & Run 3 & Run 4 & Run 5 to Run 52 & Run 53 & Run 54 & Run 55 & Run 56 \\
\hline 0.058659 & 0.065808 & 0.067969 & 0.067911 & $\ldots \ldots \ldots$ & 0.041073 & 0.040952 & 0.040867 & 0.041153 \\
\hline 0 & 0.04224 & 0.059531 & 0.06837 & $\ldots \ldots \ldots$ & 0.040878 & 0.040767 & 0.040686 & 0.04099 \\
\hline 0 & 0 & 0.042993 & 0.060104 & $\ldots \ldots \ldots$ & 0.040746 & 0.040643 & 0.040564 & 0.04088 \\
\hline 0 & 0 & 0 & 0.043455 & $\ldots \ldots \ldots$ & 0.040613 & 0.040519 & 0.040443 & 0.040771 \\
\hline 0 & 0 & 0 & 0 & $\ldots \ldots \ldots$ & $\ldots \ldots \ldots$ & $\ldots \ldots \ldots$ & $\ldots \ldots \ldots$ & $\ldots \ldots \ldots$ \\
\hline 0 & 0 & 0 & 0 & $\ldots \ldots \ldots$ & $\ldots \ldots \ldots$ & $\ldots \ldots \ldots$ & $\ldots \ldots \ldots$ & $\ldots \ldots \ldots$ \\
\hline 0 & 0 & 0 & 0 & 0 & 0.049481 & 0.041523 & 0.038171 & 0.037377 \\
\hline 0 & 0 & 0 & 0 & 0 & 0 & 0.049407 & 0.04134 & 0.037692 \\
\hline 0 & 0 & 0 & 0 & 0 & 0 & 0 & 0.047865 & 0.038824 \\
\hline 0 & 0 & 0 & 0 & 0 & 0 & 0 & 0 & 0.04059 \\
\hline
\end{tabular}


Table 6. Damage per cycle

\begin{tabular}{|c|c|c|c|c|c|c|c|c|}
\hline Run 1 & Run 2 & Run 3 & Run 4 & Run 5 to Run 52 & Run 53 & Run 54 & Run 55 & Run 56 \\
\hline 0.004188 & 0.002952 & 0.002487 & 0.002318 & ......... & 0.000500 & 0.000498 & 0.000496 & 0.000498 \\
\hline 0 & 0.005516 & 0.003708 & 0.002792 & ......... & 0.000497 & 0.000495 & 0.000493 & 0.000495 \\
\hline 0 & 0 & 0.005430 & 0.003659 & $\ldots \ldots \ldots$ & 0.000495 & 0.000493 & 0.000491 & 0.000494 \\
\hline 0 & 0 & 0 & 0.005391 & ......... & 0.000493 & 0.000491 & 0.000490 & 0.000492 \\
\hline 0 & 0 & 0 & 0 & ......... & $\ldots \ldots \ldots$ & ......... & ......... & ......... \\
\hline 0 & 0 & 0 & 0 & .......... & $\ldots \ldots \ldots$ & .......... & .......... & ......... \\
\hline 0 & 0 & 0 & 0 & 0 & 0.000581 & 0.000470 & 0.000436 & 0.000428 \\
\hline 0 & 0 & 0 & 0 & 0 & 0 & 0.000583 & 0.000468 & 0.000431 \\
\hline 0 & 0 & 0 & 0 & 0 & 0 & 0 & 0.000566 & 0.000441 \\
\hline 0 & 0 & 0 & 0 & 0 & 0 & 0 & 0 & 0.000468 \\
\hline
\end{tabular}

Table 7. Discrete $\mathrm{N}_{\mathrm{f}}$

\begin{tabular}{|c|c|c|c|c|c|c|c|c|}
\hline Run 1 & Run 2 & Run 3 & Run 4 & Run 5 to Run 52 & Run 53 & Run 54 & Run 55 & Run 56 \\
\hline 238.7731 & 338.6887 & 401.9574 & 431.3754 & ......... & 1998.0962 & 2007.6488 & 2013.4701 & 2006.4415 \\
\hline 0 & 181.2701 & 269.6318 & 358.1388 & .......... & 2009.1011 & 2018.7513 & 2024.6385 & 2016.8406 \\
\hline 0 & 0 & 184.1369 & 273.2325 & $\ldots \ldots \ldots$ & 2016.9404 & 2026.6579 & 2032.5948 & 2024.0592 \\
\hline 0 & 0 & 0 & 185.4709 & .......... & 2024.8564 & 2035.2767 & 2040.6236 & 2031.3373 \\
\hline 0 & 0 & 0 & 0 & $\ldots \ldots \ldots$ & .......... & .......... & .......... & .......... \\
\hline 0 & 0 & 0 & 0 & .......... & ......... & $\ldots \ldots \ldots$ & .......... & $\ldots \ldots \ldots$ \\
\hline 0 & 0 & 0 & 0 & 0 & 1719.8799 & 2127.0297 & 2289.5999 & 2334.3843 \\
\hline 0 & 0 & 0 & 0 & 0 & 0 & 1713.7103 & 2136.2140 & 2318.1570 \\
\hline 0 & 0 & 0 & 0 & 0 & 0 & 0 & 1764.3075 & 2267.0154 \\
\hline 0 & 0 & 0 & 0 & 0 & 0 & 0 & 0 & 2134.4035 \\
\hline
\end{tabular}

Table 8. Cumulative $\mathrm{N}_{\mathrm{f}}$

\begin{tabular}{|c|c|c|c|c|c|c|c|c|}
\hline Run 1 & Run 2 & Run 3 & Run 4 & Run 5 to Run 52 & Run 53 & Run 54 & Run 55 & Run 56 \\
\hline 238.7731 & 338.6887 & 401.9574 & 431.3754 & .......... & 1998.0962 & 2007.6488 & 2013.4701 & 2006.4415 \\
\hline 0 & 53.4759 & 109.4635 & 159.9033 & $\ldots \ldots \ldots$ & 1769.0129 & 1778.6578 & 1784.5409 & 1776.8299 \\
\hline 0 & 0 & 38.2350 & 81.1959 & $\ldots \ldots \ldots$ & 1722.2307 & 1731.9386 & 1737.8676 & 1729.5222 \\
\hline 0 & 0 & 0 & 29.1619 & .......... & 1690.6050 & 1700.9063 & 1706.3461 & 1697.3686 \\
\hline 0 & 0 & 0 & 0 & .......... & .......... & .......... & .......... & .......... \\
\hline 0 & 0 & 0 & 0 & .......... & .......... & .......... & .......... & ......... \\
\hline 0 & 0 & 0 & 0 & 0 & 22.8719 & 42.5959 & 67.0304 & 70.4559 \\
\hline 0 & 0 & 0 & 0 & 0 & 0 & 15.8912 & 41.2002 & 47.2532 \\
\hline 0 & 0 & 0 & 0 & 0 & 0 & 0 & 20.9027 & 30.6700 \\
\hline 0 & 0 & 0 & 0 & 0 & 0 & 0 & 0 & 9.1959 \\
\hline
\end{tabular}

Table 9. Total Damage

\begin{tabular}{|c|c|c|c|c|c|c|c|c|}
\hline Run 1 & Run 2 & Run 3 & Run 4 & Run 5 to Run 52 & Run 53 & Run 54 & Run 55 & Run 56 \\
\hline 1 & 0.704992 & 0.594025 & 0.553515 & .......... & 0.119500 & 0.118931 & 0.118587 & 0.119003 \\
\hline 0 & 1 & 0.792355 & 0.702832 & ......... & 0.146117 & 0.145421 & 0.145000 & 0.145518 \\
\hline 0 & 0 & 1 & 0.842767 & ......... & 0.165074 & 0.164287 & 0.163811 & 0.164408 \\
\hline 0 & 0 & 0 & 1 & .......... & 0.179476 & 0.178615 & 0.178102 & 0.178764 \\
\hline 0 & 0 & 0 & 0 & ........... & ........... & .......... & .......... & .......... \\
\hline 0 & 0 & 0 & 0 & .......... & .......... & $\ldots \ldots \ldots$ & ......... & ......... \\
\hline 0 & 0 & 0 & 0 & 0 & 1 & 0.990726 & 0.980713 & 0.979616 \\
\hline 0 & 0 & 0 & 0 & 0 & 0 & 1 & 0.988152 & 0.986471 \\
\hline 0 & 0 & 0 & 0 & 0 & 0 & 0 & 1 & 0.995691 \\
\hline 0 & 0 & 0 & 0 & 0 & 0 & 0 & 0 & 1 \\
\hline
\end{tabular}


Table 10. Total $\mathrm{N}_{\mathrm{f}}$

\begin{tabular}{|c|c|c|c|c|c|c|c|c|}
\hline Run 1 & Run 2 & Run 3 & Run 4 & Run 5 to Run 52 & Run 53 & Run 54 & Run 55 & Run 56 \\
\hline 238.7731 & 238.7731 & 238.7731 & 238.7731 & & 238.7731 & 238.7731 & 238.7731 & 238.7731 \\
\hline 0 & 292.2491 & 292.2491 & 292.2491 & & 292.2491 & 292.2491 & 292.2491 & 292.2491 \\
\hline 0 & 0 & 330.4841 & 330.4841 & & 330.4841 & 330.4841 & 330.4841 & 330.4841 \\
\hline 0 & 0 & 0 & 359.6461 & & 359.6461 & 359.6461 & 359.6461 & 359.6461 \\
\hline 0 & 0 & 0 & 0 & $\ldots \ldots \ldots$ & & & …...... & \\
\hline 0 & 0 & 0 & 0 & $\ldots \ldots \ldots$ & & & & \\
\hline 0 & 0 & 0 & 0 & 0 & 2220.511 & 2220.511 & 2220.511 & 2220.511 \\
\hline 0 & 0 & 0 & 0 & 0 & 0 & 2236.403 & 2236.403 & 2236.403 \\
\hline 0 & 0 & 0 & 0 & 0 & 0 & 0 & 2257.305 & 2257.305 \\
\hline 0 & 0 & 0 & 0 & 0 & 0 & 0 & 0 & 2266.5017 \\
\hline
\end{tabular}

\section{RESULTS}

The fatigue lifetime is often represented by the number of cycles to failure. Fatigue damage in solder layer was found due to accelerated thermal cycle. The number of cycles to failure of the IGBT module are around 2266 cycles and 2400 cycles forthermal cycles $-55^{\circ} \mathrm{C}$ to $160^{\circ} \mathrm{C}$ and $-40^{\circ} \mathrm{C}$ to $125^{\circ} \mathrm{Crespectively.Figure} 6$ shows the 2D IGBT module before crack initiation and Figure 7 shows module after crack initiation and propagation in solder layerfor thermal cycle $-55^{\circ} \mathrm{C}$ to $160^{\circ} \mathrm{C}$.

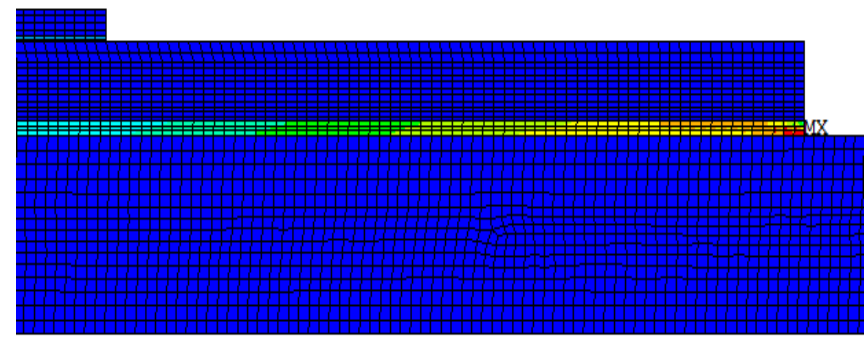

Figure 6: 2D IGBT module before crack initiation.

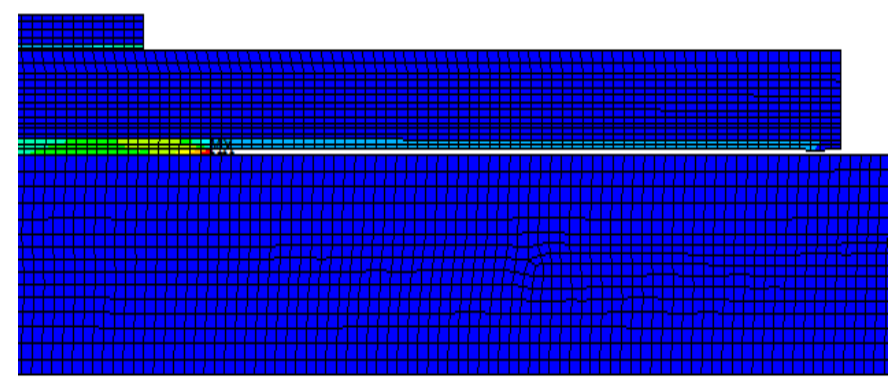

Figure 7: 2D IGBT module after crack initiation and propagation.

\section{CONCLUSION}

In this paper, 2D finite element analysis of a multilayered IGBT module under thermal cyclic loading is carried out. Damage is calculated in individual elements using E-P model coupled with SI technique. Using threshold damage criteria,the elements are killed. The crack is initiated at the outer side of the bottom solder layer interface in between base plate and substrate due to CTE mismatch. The crack is propagated towards the inner side of the bottom solder layer till it is completely delaminated.As a result delamination of solder layer, IGBT module fails to carry any further mechanical and electrical loads.Parametric study performed for IGBT module. Considered thermal cycles $-55^{\circ} \mathrm{C}$ to $160^{\circ} \mathrm{C}$ and $-40^{\circ} \mathrm{C}$ to $125^{\circ} \mathrm{C}$, we get number of cycles to failure are 2266 and 2400 respectively. Thus fatigue life is predicted for solder interconnects in IGBT module.Conclusion of above parametric study is thermal cycle $\Delta \mathrm{T}$ value decreases the number of cycles to failure increases. Future work will involvefatigue life prediction of the IGBT module by comparing various solder alloys with different thermal cycles.

\section{ACKNOWLEDGMENT}

To put an effort like this requires the determination and help of many people around me and I would not be doing justice to their efforts by not mentioning each helping hand in person.

I express my heartful gratitude to, Head of Department and other staff members of the Mechanical Engineering Department for their kind co-operation.I feel privileged to acknowledge with deep sense of gratitude to my guide Dr. F.B.Sayyad for his valuable suggestion and guidance throughout my course of studies and help render to me for the completion of the report.

Last but not the least I would like to thank my parents and my friends. It would have not been possible to complete the report without their moral support, valuable comments and suggestions which motivated me towards work.

\section{REFERENCE}

[1] Mika Ikonen,"Power Cycling Lifetime Estimation of IGBT Power Modules Based on Chip Temperature Modeling", Lappeenranta University of Technology, Lappeenranta, Finland, pp 21, 11th of December, 2012.

[2] IGBT Application Handbook, HBD87/D, Rev 2 Sep2012.

[3] Leila JannesariLadani, "Damage Initiation and Evolution in Voided and Unvoided Lead Free Solder Joints Under Cyclic Thermo-Mechanical Loading", $\mathrm{PhD}$ dissertation, University of Maryland, College Park, 2006.

[4] James D. Gyllenskog, "Fatigue Life Analysis of T-38 Aileron Lever Using a Continuum Damage Approach", PhD dissertation, Utah State University, Logan, Utah, 2010.

[5]Hua Ye, Minghui Lin, CemalBasaran, "Failure Modes and FEM Analysis of Power Electronic Packaging", UB Electronic Packaging Laboratory, State University of New 
York at Bu_alo, 101 Ketter Hall, North Campus, Bu_alo, NY 14260-4300, USA.

[6] Z. Sun,L. Benabou,P.R. Dahoo, "Prediction of thermo mechanical fatigue for solder joints in power electronics modules under passive temperature cycling", Engineering Fracture Mechanics 107 (2013) 48-60.

[7] N.Y.A. Shammas, M.P. Rodriguez, A.T. Plumpton and D. Newcombe, "Finite Element Modelling of Thermal Fatigue Effects in IGBT Modules", IEE Proc. CircuilsDevices Syst.Vol. 14X, No. 2. April 2001.

[8] GayatriCuddalorepatta, "Evolution of the Microstructure and Viscoplastic Behavior of MicroscaleSAC305 Solder Joints as a Function of Mechanical Fatigue Damage", $\mathrm{PhD}$ dissertation, University of Maryland, College Park, 2010.

[9] Leila JannesariLadani, "Damage Initiation and Propagation in Voided Joints", Department of Mechanical and Aerospace Engineering, Utah State University, Logan, UT, 84341.

[10] Daniel M $\quad$ Farley, Professor AbhijitDasgupta,"Development of Fatigue Models for Copper Traces on Printed Wiring Assemblies Under Quasistatic Cyclic Mechanical Bending", PhD dissertation, University of Maryland, College Park,2010.

\section{BIOGRAPHIES}

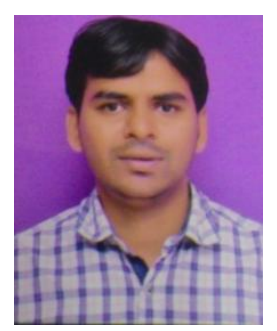

Dipesh Kumbhakarna, an bachelor of engineering (Mechanical) from Pune university. He has worked on company based projects that involve finite element analysis and currently pursuing master of engineering (Design) from Pune university. Also published many technical papers in conference.

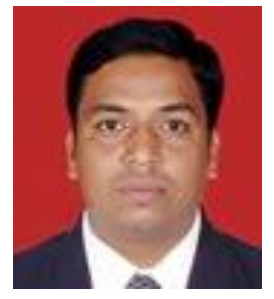

Dr. F. B. Sayyad, an professor at the department of mechanical engineering, G. S. Moze college of engineering, Pune. He has Ph.D in mechanical vibration with experience in the field of mechanical vibration. Also over one decade experience as professor in the field of mechanical engineering. Additionally published many text books, papers (in international Journal).Working as an Editorial Board Member for Journal of vibration and measurement and Control, Columbia International Publication, USA. 